\title{
Performing Arts in the Zapata Swamp: A Legacy of the Cuban Revolution
}

\author{
Rosana Herrero Martín Interviews Yander Roche (Aka 'Cuco'), Artistic Director of Korimakao, the \\ Cuban Community Arts Troupe
}

\author{
Rosana Herrero Martín
}

Antigua State College, University of the West Indies, Antigua

Copyright $\bigcirc 2016$ by authors, all rights reserved. Authors agree that this article remains permanently open access under the terms of the Creative Commons Attribution License 4.0 International License

\begin{abstract}
The purpose of this conversation is to investigate the symbiotic framework governing art and the socionatural community where it grows and develops. Our case study will feature the unique binomial that we find in Cuba between a community arts institution (KORIMAKAO) and the unique ecosystemic, social and historical environment that propels life and meaning to the project since 1992 (the municipality of Cienaga de Zapata, about 180 kilometers south of Havana). Korimakao, with its twenty-four years of experience bringing art and aesthetic sensibility to the remotest population pockets of Cuba, aims to become pioneer Centre of Caribbean and Latin American Communitarian Art. In the language of the first Siboney nomadic inhabitants of the Zapata Swamp, 'Kori' means man and 'Macao' the arthropod that takes refuge in the shells of certain mollusks. There we go, Korimakao, a semisedentary living organism, fusion performing arts school (theater, dance, music) consisting of over 80 young artists, who every summer during the months of July and August, and not unlike Lorca's legendary La Barraca travelling theatre, take their backpacks and their idiosyncratic stagings on a tour across the eighteen communities that make up the Zapata Swamp, delving into the identitarian and ecological roots of their beholders.
\end{abstract}

Keywords Korimakao, Yander Roche, Community Arts, Zapata Swamp, Cuba, Performing Arts

\section{Korimakao: General Coordinates}

\section{Thanks for accepting my invitation, Yander.}

It is a pleasure.

Why this name, Korimakao? Tell us about the etymology of your company's name.
In Arawak language kori stands for human being, and makao is an arthropod living in the shells of some mollusks, such as snails. The term korimakao was in fact used by Cuban aboriginal people to define other tribes' nomadic lifestyle.

The term basically assists us in the conceptualization of our arts troupe, featuring youth from all over Cuba providing artistic service to various community spaces, carrying along their art, identity and vocation.

With what performative-revolutionary mission in mind was Korimakao born? [Tell us, Yander, about that constellation of historical, socio-cultural, individual and communitarian coordinates, that converged in the Zapata Swamp back in 1992, year of Korimakao's foundation, and made possible the creation of your communitarian performing-arts troupe]. Also, from 1992 to 2016, in what ways has that original performative-revolutionary mission evolved?

Well, everyone knows that in 1992 we were in the midst of the Special Period, a time that for Cuba accounted for absolute lack of material and financial resources at all economic levels and that strongly impacted family economy, consequently resulting in an abrupt and accelerated change in the system of values, expectations, dreams and interrelationships within our country's social and cultural domains.

In this regard, the Zapata Swamp did face dire straits at the time, as the rest of the country did, but in a lighter form. Due to its special geographical, historical and strategic features, the Swamp was, and still is, inserted within the so-called Turquino-Manatí Integral and Sustainable Development National Plan (1987- ), which has since its inception prioritized healthcare, food and electricity access, socio-cultural, as well as environmental programs in mountainous areas of Cuba with difficult access, such as the Zapata Swamp.

And it was at this point in time, in 1992, in the early stage of the Special Period, as we were all wondering what we would eat the next day, that two lucid lunatics met and 
together envisioned an artistic community movement for the Zapata Swamp. One of these lunatics was Faustino Pérez, commanding officer of the Revolution, who at the time was in charge of the integral development at the Zapata Swamp. The other was Manuel Porto, an important Cuban TV and Film actor who at the time was filming a famous soap-opera called Cuando el agua regresa a la tierra (When the Water Returns to the Soil), which was basically set in this swamp.

Commander Pérez's original thought was indeed widely and deeply revolutionary, the idea that there was no possible way to conceive a society's/community's integral development, without the participation of art.

A turning point within Korimakao's initial course, was Faustino Perez's untimely death short before our very first premiere in 1992 (La hoguera - The Bonfire). It was not easy to dissuade the Swamp authorities from the defeatist idea that the community art project was dead and buried with Commander Pérez, nor to justify the spiritual need for art when the material need for food was so flagrant. And this was largely Manuel Porto's achievement, who picked up Commander Pérez's baton with all his heart and will power. Thanks to Porto, for instance, Korimakao has now decent headquarters in the Swamp settlement of Palpite, in what used to be the warehouses of a construction company, leaving behind years of nomadic camping existence.

In 2001 Fidel Castro visited Korimakao and breathed new encouragement and support into Porto's dream to make Korimakao evolve into The Latin American Centre for Community Arts, and which right now is our main objective.

All these years Commander Perez's original mission to generate an art community movement that would work in the Zapata Swamp nourishing the spirit of its people, elevating their aesthetic taste, contributing to the territory's cultural development, is still at the core of our endeavors. Obviously it has been enriched with new blood, widened with experience, solidified with acquired competences. In this sense, we have also broadened our scope beyond the Zapata Swamp territory. For instance, we have provided artistic post-hurricane services in the Cuban province of Pinar del Río, in communities that were literally devastated. We have performed in the Escambray Mountains; we have travelled all the way to a remote hamlet in Isla de la Juventud (Island of Youth), to present a function to one single little boy living in the community of Cocodrilo; we have given performing arts workshops in socially discriminated barrios of Caracas and Paris, etc. That is Korimakao's spirit.

What does the territory of the Zapata Swamp represent to Korimakao? And what does Korimakao represent to the Swamp? To what extent is the relationship between Korimakao, the communitarian arts troupe, and the Zapata Swamp, the socio-natural space where it is based, a symbiotic one? What would become of Korimakao if rooted out of the Swamp? What would become of the Swamp if bereft of Korimakao?

The Zapata Swamp is a very singular place. Its geographical and historical features have certainly determined its peoples' behavior and the region's culture.

The cenagueros, as the Zapata Swamp people are known in Cuba, are not farmers, but fishers, pickers, hunters, charcoal makers. And it is around these subsistence activities that the Swamp's collective imaginary and culture has evolved along its history. In this sense, Korimakao's idiosyncratic micro-culture has certainly been molded by the singularities of the space where we are based.

I am not so fond of the notion of symbiotic relationship here, since that would imply that both species is able to live without the other, and I believe it would be Korimakao the one unable to live without the Swamp, rather than the Swamp without us.

We are basically rooted here. We simply cannot uproot this place from here. And if we were to do our work somewhere else, it would be surely something else. Somehow, in a spontaneous, unintended and weird way, we have transferred the Swamp's daily nature into our creative processes as an artistic community set deep in the Swamp territory. With its isolated and unnoticed natural setting, the Swamp has actually provided Korimakao with a consistent line of values all these twenty-three years of existence. The Swamp has allowed us not to lose our essence, despite the many changes experienced.

Korimakao is still a unique opportunity in Cuba to grow as a young artist you will not find anywhere else. It is still a place to raise one's essential individuality, one's independence of mind and spirit - an enclave of resistance.

Without Korimakao, the Zapata Swamp would not disappear, but it would certainly lose its last chance to transcend all this current rampant pseudo-culture and anti-values we are bombarded with across global media.

Tell us, Yander, about the creative process behind each stage project pursued by Korimakao: conception, dramaturgy, direction, actors'work, multidisciplinary work, space-time coordinates, conditions, etc.

Let's talk then about two of our annual most important creative processes, the ones with largest scope and impact both internally and communally. One is the production we put up every $18^{\text {th }}$ of April as part of the celebrations that commemorate every year Playa Girón Victory, and which we have carried out without a break over the last twenty three years. The other one is our summer tour around the 18 communities living in the Zapata Swamp. This year we are also celebrating our $20^{\text {th }}$ summer tour.

The Playa Girón Victory production usually takes three months to create: script or dramaturgy, staging, original musical arrangements, orchestration of pre-determined music, choreographic work, costumes and scenography design, design execution, light design and set up, technical and partial rehearsals.

Such a project takes both the individual vision of the artistic director as well the active participation and co-management of our multidisciplinary casts.

On plenty of occasions we have worked with material first erratically generated out of various stylistic, thematic, 
emotional proposals from our different creative nucleuses (choreography, dramaturgy, music, visual arts), then gradually becoming a kind of consensual 'show mass' (featuring movements, voices, texts, sounds) which will later be channeled within a pre-defined dramaturgical context or one conceived on the basis of what was originally generated.

For Playa Girón Victory production we like to work at the junction of different performing-arts expressions, in the vein of the customary Cuban variety show, a tradition that unfortunately is rather deteriorated, almost lost nowadays, and which we realize it is important to pick up. This mission represents a huge artistic and financial challenge, as you can imagine, to put our artists to dance, sing, play, interpret, all to a top national event level. There is no room for botch here. There are certain creative, stylistic and ideological standards we need to meet.

Now, about the summer tour, it is not just the typical tour, where one gets to the place, performs and goes back to the hotel to sleep. This is a process of two-month communal living across the communities and settlements around the Zapata Swamp. It is not many people that live in them, but each of them is a different world and each has uneven infrastructural and cultural conditions, occasionally disparate. For instance, we go to a place like Girón, and we experience its relative economic development, its buildings. Then we go to Santo Tomás, a twenty-house settlement, and we have to deal with a six-hour electricity flow per day and plenty of mosquitos; or Guasasa, on the coastal area, where we sleep on the sand, out in the cold and wet.

In its original conception, each stage of the tour included a theatre night, a dance night, a musical night and some children's and teenagers' matinées, which may include creative workshops.

Some years ago we introduced what we call a program tour, by which every night we present a different program featuring all performing-arts manifestations: a theatre play, a dance show and a musical concert or descarga. The matinées have always been there.

Since the tour is a once-in-the-year opportunity for this particular population sector, we believe it is very important to bring them as many quality and varied artistic proposals as we possibly can, a scope that is precisely in line with our founding spirit.

We have gotten to put together a maximum of seventeen shows into one single tour: choral music, boleros, trova, popular Cuban dancing music; different theatre presentations; multidisciplinary acts; six or seven musical concerts, etc.

As our name suggests, we (over 80 troupe members) travel with our home, our food, our charcoal, our gas oil, on our backs to these places where there is nothing, we mount the stage, the lights, the sound, we set up the gallery, the theatre, the concert hall. Always counting on the resources we bring with us: two trailers, buses, so as to accomplish our missionary vision to get the staging quality of the capital cities, to make magic happen, in those communities with no access to such aesthetic products.

The effort is indeed titanic, but it makes all the sense to us, for as Pope Francis said during his recent visit to Cuba, "whoever does not live to serve, does not 'serve' to live".

As Korimakao's artistic director, which are the theoretical and practical sources you nourish from? What about Korimakao's performing artists? What kind or relationships emerge between you all? What responsibility does each one of you have within Korimakao's creative process?

I am an artistic director with a very diverse artistic training, quite empiric. One thing is true, I have always tried to learn as much as possible. It is a long time since it is clear to me which are my closest sources for creation. Above all, my experience at Korimakao. Secondly, collective movements, in particular the following experiments: Escambray Theatre in Cuba, Boal's Theatre of the Oppressed in Brazil, Latin American Spontaneous Theatre, Playback Theatre, and other improvisational theatre making, as well as Performance Art.

In my work with actors and dancers (all moving beings on stage) I have been deeply marked by Eugenio Barba's Theatre Anthropology and his Odin Theatre. An even though Barba does not particularly like being mentioned as a theoretical source and methodological inspiration, that is precisely what he is to me and as such his work is very important in my creation.

Other artists within the troupe take various theoretical perspectives for their artistic reference, such as Stanislavsky, Theatre Anthropology again, Cuban popular music, African and Cuban peasant dance folklore, Cuban ballet and modern dance techniques (core training elements for our dancers really), Pina Bausch and contemporary dance, jazz, pre-Columbian, Mexican, Latino muralism, etc.

Korimakao is a community, in the widest extension of the term, and as such it is impossible to separate the professional and the personal component within our interpersonal relationships. We live right here, we do not go home at the end of the day, which makes it all complex and intense indeed.

In terms of Korimakao's organization chart, within the Directorate-general of the troupe, we have two sections, the Directorate-general for creative aspects, with the general artistic director, as well the creative management board, which includes the directors of the different specializations (theatre, dance, music, audiovisuals, visual arts, production).

On the other hand, there is a Directorate-general for technical media: lighting department, sound department, which ties up, in an organized and integrated way, all Korimakao's processes of artistic creation.

Relationships across this hierarchical structure are both formal and informal. The level of formality is obviously entailed within the responsibilities you assume within your staff role. Informal relationships in Korimakao occur through the manifestation of individual leadership in the course of professional practice and demonstrated capacities.

It happens all the time. Let me put an example of this. A dancer, an actor, a technician, of great potential and initiative, starts to spontaneously collaborate with, even to advise, 
somebody in the troupe with a formal role. In Korimakao we particularly welcome that. All the formal leaders in our space have gradually emerged out of displayed informal leaderships. In our troupe graduates from professional schools co-exist with street artists. Everybody is here treated according to what they are able to do, to demonstrate. No matter their academic degrees or whatever they say they may be able to do.

Which oral, performative, theatrical, musical, dance, and visual traditions do Korimakao's stage productions draw from?

In terms of oral heritage, the source of nourishment has been diverse. On the one hand, in its twenty-three years of existence, Korimakao has been profusely inspired by two national $20^{\text {th }}$-century literary figures, Onelio Jorge Cardoso and Samuel Feijoo, whose short stories and ethnological essays are essential for the understanding of Cuban popular and rural culture. On the other hand, we have also made creative use of indigenous oral sources, that is, from the Swamp settlers, the eldest ones. We also draw on many occasions from the past and present oral legacy in our own provinces all over Cuba.

In terms of influential theatrical forms, undoubtedly, the Escambray Theatre (1968- ) has been a landmark for us with their participatory 'nuevo teatro' and their socio-cultural theatrical experiments. Significant for us has also been the movement of collective creation within Latin American theatre in the late $70 \mathrm{~s}$ and early $80 \mathrm{~s}$, with major exponents, such as La Candelaria Theatre Company in Bogota (Colombia). We pay likewise attention to the oral narrative performance practice, experiencing a strong momentum in Cuba at the moment. And last, but not least, the notion of the Cuban entertainment show, which unfortunately has largely faded away with the passing of time, has definitely left its imprint on Korimakao's re-appropriation of the variety acts tradition to our own context, with our own artists, realities, as well as production capacities.

As regards musical influences, we basically draw from the wide range of Cuban rhythmic formats: the septet, the traditional trio, the choir, the jazz band.

In terms of visual arts, we have developed a close bond with Latin American muralist heritage. Murals certainly play a central role within the set design conceived for our productions.

Finally, I would highlight the eclectic notion that pervades the agglutination of all artistic manifestations within our stage production, and that we find to be an apt mode to promote traditional, contemporary and universal arts.

\section{Which are the thematic priorities within Korimakao's stage repertoire?}

Our most recurring themes are historical, socio-cultural, environmental and political.

We are an artistic troupe of the Cuban State, subsidized by the Cuban State, in step with our country's social project. That is why we are here, serving our art to these rural communities. That itself has been an important theme in our stage productions: the defense of our social system; the defense of our cultural identity; the defense of our historical values from a plural outlook; the dimension of the children's innocence; the promotion of creativity and imagination; the advocacy for the conservation of the Swamp natural resources and its native animals.

\section{Korimakao: The Cuban Community Arts Troupe}

Community art is associated with artistic practices "seeking an engagement with the social context, pursuing, beyond any aesthetic achievement, a social benefit or improvement, and above all, to endorse collaboration and participation from the communities involved in the work's accomplishment" (Palacios 2009: 199).

How and to what extent is Korimakao integrated within this theoretical framework? For it is well-known that Korimakao, since its inception, has precisely emphasized the primordial artistic quality of their projects, along with their socio-cultural empowering mission within the Swamp and its people. What accounts, in your opinion, Yander, for this partial and idiosyncratic dissociation on the part of Korimakao from the theoretical assumptions that internationally define the term "community art"?

I do not think that in order to be committed with a community one may need to neglect aesthetic goals and accomplishments. The bigger and more ambitious the execution of our artistic proposals, the bigger its significance, as well as the bond, impact and the transformation to be generated among the communities.

This is a complex mission for us, due to the limited level of instruction on the part of our audiences. But that is precisely part and parcel of our work, namely, to assume the challenge it represents to elevate our communities' level of aesthetic appreciation, their understanding of the world, broadening their cultural models through art, which is indeed the ideal and most impactful instrument to do so.

The mission of an arts community project is not that of a Messiah who comes to save people's lives. It is all about the impact we may leave on our communities' critical thinking, values, and ideologies. It is obvious we cannot solve none of their food, environmental, economic problems - I wish we could -, but we can actually have an influence on our people's thoughts, empower them to manage their realities, solve their individual, interpersonal and communal problems.

From that point of view, during these twenty-three years we have made a significant contribution to the Zapata Swamp. We have had many local people working at Korimakao since its foundation. Their encounter with art, creation, sensibility, humility has radically changed their lives. Several generations of audiences have also been participants of our art. We no longer get the same old 
reactions and expressions before the aesthetic event as we used to. Recently at the II National Creation Workshop we had two thousand people at the Caletón Esplanade, watching a performance by the Chilean contemporary dance company Danza Espiral, featuring highly conceptual codifications, in a respectful and appreciative way. This would have been highly unlikely at the time when Korimakao was founded. Can you believe that people attended the premiere of $L a$ hoguera (The Bonfire) carrying stones and tomatoes to throw at the artists?!

Talking about art in the Swamp is no longer "aliens stuff", but a daily occurrence. Thanks to such an achievement people in the Swamp can now appreciate and filter, in a more active way, the different processes and messages conveyed by each Korimakao performance, as well as by other national and international troupes that collaborate with us.

One can always do more and better, for sure, but Korimakao needs to be analyzed through a holistic lens, from its very inception. The thing is, Korimakao is still there, in a highly shifting context. Of course, it needs to adapt itself, in order to go on surviving, in order to accomplish a mission, one that is more challenging than ever before, perhaps as challenging as it was back in the nineties.

- Likewise, community art has a strong educational purpose and meaning in its emancipatory sense as tool for human development. In this sense, the educational potential subscribed by community art is primarily based on Paulo Freire's critical pedagogy and its three pillars: dialogue as referential artist-community bidirectional learning, the transfiguring power of education, as well as culture's regenerative capacity.

In this regard, Yander, can you to tell us about the particular process of recruitment conducted by Korimakao among its members?

Our recruitment process is twofold: the more traditional one takes place through national calls or individual spontaneous engagement to become part of Korimakao. We usually audition candidates in the field(s) of their interest, and we also conduct an interview with each of them to detect certain personal virtues, such as their service vocation and the potential alignment of their personal desires and aims with the objectives of our institution. In the last three years we have introduced another enrolment method, by which we go to the different provinces and municipalities to conduct the auditions. This allows us to get to know first-hand the realities in other parts of Cuba, to meet people in their own context and to have a higher impact at a national level.

-According to Sally Morgan, Great Britain's community art pioneer, the empirical component essentially defines the community artist's effort and training: through trial and error, "testing, assessing, adapting" (Palacios 2009: 204). How empirical is, in this sense, the artistic experience/education of Korimakao's young members?

I would say around a $90 \%$. We are a very empirical troupe, both conceptually and performingly speaking. First of all, we work with artists, technicians, producers, assistant directors, who in most of the cases have not had any previous formal artistic nor community training. Our company is not a school in the strict sense of the term, but a space where work and learning processes coexist through practical experience, individual and self-taught study.

Yes, this is a term that binds us to our very essence: "empirical".

- Let's talk about the Zapata Swamp, its people, the cenagueros, and Korimakao's site specific work that emerges from this context and community (Palacios 2009: 200). To what extent are Korimakao's stage projects determined by the Swamp's physical, human and social location, as well as by its people's realities? Who decides what social, environmental, historical, issues are to be addressed and enacted? In this regard, how do Cuban cultural official institutions and curators define their roles within Korimakao's stage repertoire?

My answer to your question is filtered through my six-year experience in the Swamp. The Zapata Swamp is a complex and difficult place in which a unique constellation of distinct natural, historical and political conditions.

Before the triumph of the Revolution, the Swamp was known as "the Cuban Amazon". Its population was completely marginalized, exploited, and lacked healthcare and infrastructure conditions.

The Revolution introduced radical changes and improvements into the Swamp, paying prioritized attention to a region that had suffered decades of neglect and oblivion.

As a billboard says at the entrance to the Swamp: "Everything you see here is the work of the Revolution": roads, electricity, tourism development, healthcare, public education. Right before the Special Period, whereas the rest of Cubans had to pay a symbolic fee for medicines, the cenagueros had them all free. They also benefited from food extras in their basic basket: beef, canned food, rum and wine.

Nowadays the cenagueros have unfortunately lost a great deal of their cultural values, history, identity and sense of responsibility with the benefits the Revolution put in their hands.

Korimakao's stage projects are fifty per cent determined by the Swamp and its peoples' realities, and this is so because we care and because we are called to work from the collective imaginary, history, values and often from the community preferences, but above all, we are called to extend all these referents, to impact these minds from an educational point of view, to build and create a taste, because taste may be elaborated and influenced upon: we are called to build a taste for the aesthetically beautiful, to work towards the communities' spiritual well-being.

Our dramatic, musical and audiovisual productions have been at times warmly welcome by the audience, at times though, due to the concepts, themes and treatments introduced, they have been rejected by the community, but 
still people have attended the show, they have participated and freely reacted. Participation not only involves clapping and enjoying a play, it may also entail to question, speak up to sabotage what is happening on stage. If you do not leave the auditorium, if you stay there, you are participating indeed, even if that form of participation on the part of the settlers-spectators may be a source of frustration for the artist.

Popular, cultural and political authorities make occasional proposals to us regarding our stage repertoire, but nobody tells us what to do, let alone approves our choices. It is always Korimakao's Council of Experts that decides which are the most adequate productions to put up every year.

- Community art is particularly attentive to the identity processes both within the community and the artist. In this sense there are authors who recognize Community Arts/artists for their open training and mutable makeover, as well as for their permanent negotiation status by meeting with others (Kwon, 2001). On the other hand, there are other authors who propose the concept of "politically cohesive community" which is the result of a complex process of political self-definition developed against a collective mode of oppression (race, gender, class, etc.), but also emerging within a framework of shared culture and discursive tradition (Kester 2004: 150).

In light of this perspective, there are three issues that I would put on the table:

Firstly, what type of identity model would the Swamp community and its people subscribe to as solid interlocutors for Korimakao's community-based performing-arts projects?

Secondly, what type of mechanisms, in terms of real two-way dialogue, review, self-criticism does Korimakao implement with the dangerous advent of partial readings of the identities, histories, territorial and social relationships within the communities it is intended to work with, in order to avoid lapsing into misunderstanding, mystification, manipulation or instrumentalisation of certain groups, historical events, biographies, etc., both by the artist, as well as by the institutions supporting, organizing or financing each of its community-based stage projects? Thirdly, how does the current exodus of Cubans affect both the population of the Swamp, as well as the young artistic community of Korimakao? How does the exodus of cenagueros and korimakaos challenge your artistic project? Does this theme of identity feature Korimakao's stage projects?

I believe the Swamp and its people are not fully circumscribed to either identity process suggested, but at the same time they are not excluded from either of them. In the Swamp there are actually different micro-identities co-existing nowadays. In the southern settlements, such as Guasasa and La Ceiba, we find ricefield farming, horse breeding and fisheries. In Playa Larga and Playa Girón, the two urban centers of the Zapata Swamp and the two areas with biggest economic and infrastructural growth, the cenaguero there does not fish, does not hunt. People there are more involved with tourism and public administration. Also Cayo Ramona has some infrastructural development. And then we have Santo Tomás, for instance, in the midst of the bush, dealing with other issues, such as poaching and logging, featuring very particular identity traits.

The triumph of the Revolution, as mentioned before, has been a watershed for the making of the Swamp identity. Presently, on the other hand, the Swamp is experiencing a further fragmentation of its identity manifestations, due to the evolving migratory processes, such as the arrival of people from the eastern region of the country, the exodus of an important part of the Swamp population to other parts of Cuba and the world, or the imminent exponential touristic growth of the area. As I speak, a new identity is in the making in the Swamp. It is all happening incredibly rapidly, and Korimakao, as the community arts institution in the Swamp territory, is fully aware of the fact that it is of vital importance to sit down to filter all these new realities through our creative lens, in order to keep up our dialogue with the Swamp communities.

-In view of what we might call Community Art contextual bent, we also find the attempt to develop new forms of involvement and participation within the work on the part of the audience, resulting in the overcoming of the traditional work-viewer relationship interaction, as well as in the establishing of an interactive dialogue with the viewer, which is necessary to complete the work.

To which extent are Korimakao's stage proposals
'dialogic'? How does the audience attending a Korimakao's stage production interact and collaborate?

Korimakao's stage proposals have aesthetically and technically amalgamated along these twenty-three years of existence, which means that we are open to a wide range of possibilities: from the more participatory options, such as collective creation or techniques from Boal's Theatre of the Oppressed and the Latin American Spontaneous Theatre, to Performance Art, public interventions, street theatre, etc.

Important for us is to keep the equilibrium -or the tension if you want- between the bidirectional and the unidirectional dialogue with our audiences, with the desire and the intention of achieving deeper dialogues with our immediate interlocutors.

-Which are the aesthetic values pursued by Korimakao in its stage productions? Are there other priority values underpinning Korimakao's performing arts projects?

We are an eclectic group, and for that reason, we do not prioritize any style in particular. Our style is manifold. Korimakao endorses the capacity to absorb - not in the guise of a collage, nor of a gratuitous superposition-, to combine the agglutinating visual force of the actor/dancer with various aesthetic approaches within multiple performing 
manifestations, all within one single multimedia spectacle. In Fernando Ortiz terms, a spectacular ajiaco true to our artistic and cultural idiosyncrasies.

-What funding model is Korimakao consolidated upon? Is an autonomous management model feasible/desirable for performative artistic communities such as Korimakao in Cuba today?

The Community Art Troupe Korimakao is consolidated upon a funding model that in Cuba is known as "budgeted unit"

We are entirely subsidized by the Cuban State, through its provincial department, in this case the province of Matanzas. We are in the Zapata Swamp, yes, but under provincial subordination, due to the magnitude and importance of our institution.

We do not generate a single cent to the Cuban State, since everything we do is for free. People working here do receive their salaries, but our artistic performances, our children's workshops, the events we organize, are all free of cost to the communities.

I do believe this funding model is feasible, and it has proved to work all these years. What happens is that in Cuba we are now living a different moment. In accordance to our country's petition to look for ways of partial self-funding, in Korimakao we are currently considering other mixed models of management contemplated within the national legislative framework that would allow us to keep our public budgeted component, as well as to explore the commercial potential of our cultural products and services (I am thinking of the many tourists that visit us every year), and above all, to remain true to our essence and to solidify our social mission.

This is actually no contingent proposal, but a central initiative of Korimakao's co-founder, Manuel Porto, who even discussed it with Fidel at the occasion of the latter's visit to us in 2001. Namely, the creation at Korimakao of an International Center for Community Arts.

Right now, with the current legal context existing in Cuba for the first time ever, we are in the position to commit ourselves as a referential center for community arts across Latin America.

-Generally, conventional criticism has shown great disinterest in community art (the so-called'discredit of the participatory', Palacios 2009: 208), and has not looked beyond mere political or social activism.

Is this different in Cuba? How has criticism depicted Korimakao? What rank of appreciation does Korimakao hold within the broad artistic spectrum that characterizes the island? In your opinion, Yander, which are the most appropriate evaluation and analysis criteria to address the performative-community sphere?

In Cuba that aspect is not very different. Community art has its own room for reflection, but it is not at the epicenter of the important and visible spaces of artistic reflection.
Community art may be highlighted in Cuba, it may be taken better care of than in other parts of the world, but we are still very far from getting critical insight, visibility, acknowledgment.

Criticism presents us as a community group based in a remote place called Zapata Swamp. There is a very discreet approach to Korimakao's endeavors. Even after all these years of impactful work and participation in Cuba's most important performing arts festivals, critics still do not recognize the scope of Korimakao's contribution nor the troupe's artistic values. Yes, you do get the last page, a tiny little paragraph in the review Conjunto from Casa de las Americas, and an occasional article in a newspaper. Yes, but the specialized arts publications in this country usually do not include Korimakao, not even to disapprove us, and that is perplexing. It is neither good nor bad. We seem to be tolerated within a quiet distance.

-Tell us a little bit about Korimakao's presence, experience, outside Cuba, as well as the interest its performative-community project has been able to raise abroad. (Visits, exchanges, collaborations, reviews, studies, research, media, diaspora, etc.)

Korimakao is a rara avis, as exposed before, and for international public it is even more of a rara avis, in that it is an experiment based in a remote place of the world, of monumental dimensions, subsidized by the Cuban State, featuring street artists who get paid for what they do and are treated as professionals, doing art for everybody for free. This is something you cannot find anywhere else, and for the capitalist mind, which is the most abounding one in today's world and stems from this market economy mindset, by which everything must have a price, our project comes as mystifying and very hard to understand, for it finds no referent to compare it to.

The truth is that the world has come more often to Korimakao than Korimakao has come to the world. We have been to Caracas, to its popular barrios. Over twelve times now we have been in France with a philanthropic and community annual exchange program we have with the French association Stage Shepherds, which specifically deals with youth and social issues. Every year, a delegation from each troupe visits each other and gets involved in collaborative and community creative projects designed by both institutions.

We are open to and do welcome artistic exchanges. That is our goal indeed: to become a confluence space for different community art experiences that may enrich all participants.

Tens of thousands of tourists from over 17 countries have visited our premises. They look at Korimakao as "a paradise in the midst of the swamp": an exceptional place they would like to have in their own countries, a completely sui generis space, which according to at least $80 \%$ of them, is the best attraction they have visited in Cuba, an emotional and moving experience, unique in its structure, philosophy, work dynamics, in the humbleness displayed by its artists, in their 
vocation of service, as well as in the government's will to maintain a place like this, so that it may keep nurturing peoples' dreams and spirituality.

Furthermore, various universities in the US are partnering up with us in the arrangement of one-week and five-day visiting programs for their students.

Once at Korimakao we also enjoyed the visit of a group of communicators and artists from Argentina. They stayed for a whole year with us!

We have also received visits from the Dutch National Television, CNN, Telesur, among other international channels, which have covered our annual Playa Girón Victory stage production.

It is a real pity, but there has been very little done in terms of research about Korimakao's huge twenty-three-year-old sociological experiment and experiential lab. Unfortunately, we have lacked a theoretical accompaniment from our part or from Cuban or foreign institutions that would have systematized Korimakao's experience. That is a weak side of us, indeed. We are so empirical, so practice-oriented, that we have lost the scientific heritage that we have built up here, for that is surely what we have done.

There are plenty of ex- korimakaos all over the world. There is even a website where they meet, especially the first years after they leave Cuba. It is a natural process. They share nostalgic memories online, they meet in Cuba whenever they can, they keep each other updated. Some of them have even tried to set up experiences like this in their new realities. But they are all marked by this sense of Korimakao belonging, and they all agree that being here was something important and transfiguring in their lives.

-As mystical incarnation, with its exempt status within society, art / the artist can reach places where socio-political conventions cannot or will not reach (Palacios 2011: 16). In this sense, what are Korimakao milestones to date? Are there still 'summits to conquer'?

Yes, I do believe Korimakao is a mystical being, because of the simple fact of having survived, with vision and resilience, against all odds, including internal disagreement, for not everybody was convinced at one point of the necessity of such a space, nor of having it built here.

Yes, Korimakao is a real myth.

Milestones?

La hoguera (The Bonfire), our first play, written by Saul Roger, which we have put up twice, once in 1992 and the second time in 2012; the twenty consecutive Summer Tours so far, among which I would recall the one under the title "Los caminos no se hicieron solos" (Roads were no made alone), when the hurricane took it all away, the same edition when we started to work on a profounder notion of the program tour; our twenty-three commemorative Playa Giron Victory productions, which have definitely been decisive in the way art is currently appreciated in the Swamp; our Eshu y el viento (Eshu and the Wind), a one-man show inspired in the Afro-Cuban Yoruba mythology, with over 200 performances all over Cuba; and among the more recent stuff, I would point out Nuestra América (Our America), with which we have begun to explore a new aesthetic, a different kind of dramaturgy, a more holistic approach, so to speak; and finally our last production, El pequeño príncipe o ...si un Sueño elige esta Tierra..., (The Little Prince or If a Dream Chooses this Land), which is a very particular musical that lays the groundwork for our next productions, which take the notion of a magnified visual synthesis as point of departure.

-Recently, the Community Arts and the field of sustainability or environmental action have begun to interact, including creative revitalization projects in both urban and rural contexts. In this sense, it is interesting to note that since its beginnings as an artistic community entity, Korimakao has subscribed, among its primary objectives, to the development, promotion, as well as the intervention of ecological and environmental consciousness through its stage productions. How does this goal materialize, Yander, within an ecosystem of unique features such as the Zapata Swamp? (Just to remind our readers: The Zapata Swamp is the largest municipality of Cuba; it has the country's lowest density of population; it is the largest wetland in the Caribbean; it is Cuba's main paddyfield; Biosphere Reserve, RAMSAR Site, National Park, home to a large number of endemic flora and fauna; as well as unique historical scenario of military resistance during the Cuban Revolution.)

You cannot be in the Swamp and ignore Nature. Nature is everywhere here: we breathe It, we live in the midst of It. From the mosquitos, the frogs in our bathrooms, to the majás (Cuban indigenous boa), they all share Korimakao's home with us. That we cannot ignore.

Aware of Nature's omnipresence, we have many times thematised in our productions the environmental consciousness and the need to conserve and protect a place like this. In this sense, we have on two occasions opened a TURNAT meeting in Cuba (Evento Internacional de Turismo de Naturaleza - International Ecotourism Meeting).

In many children's plays, musical plays and other shows we have aimed at the representation of Nature in the Swamp and at the conservation and protection awareness on the part of its communities. In the play Humedales (Wetlands), for instance, the Swamp's sonority was recreated by the dancers and the orchestra.

In the tenets of what we intend to be the Latin American Centre for Community Arts (Centro Latinoamericano de Arte Comunitario, CLAC) this environmental perspective is centrally contemplated in terms of sustainability as indicator of Korimakao's evolutionary process, as well as of our interaction with our environment: recycling, natural friendly spaces and behaviors, access to job opportunities for local people, in order to minimize poaching and excessive hunting of animal species in the area.

It was wonderful to talk with you, Yander. Thanks and long 
live Korimakao and its Latin American Centre for Community Art.

Thanks to you, Rosana. We are here to serve.

\section{REFERENCES}

[1] Barba, Eugenio. The Paper Canoe: An Guide to Theatre Anthropology. London and New York: Routledge, 2005 (La canoa di carta, 1993).

[2] Boal, Augusto. The Theatre of the Oppressed. New York: The Theatre Communications Group, 2007 (El teatro de oprimido, 1974).

[3] Frederik, Laurie A. Trumpets in the Mountains: Theatre and the Politics of National Culture in Cuba. Durham and London: Duke University Press, 2012.
[4] Freire, Paulo. Pedagogy of the Oppressed. New York: Bloomsbury, 2000 (Pedagogia do Oprimido, 1968).

[5] Kester, G. Conversation Pieces. Community + Communication in Modern Art. Berkeley. University of California Press, 2004.

[6] Kwon, M. One Place after another. Site-specific and locational identity. Cambridge, Massachusetts. The MIT Press, 2001.

[7] MORGAN, Sally. "Looking back over 25 years". In Dickson, M. (ed.) Art with People. Sunderland: AN Publications, 1995.

[8] Palacios Garrido, Alfredo. "Arte y contextos de acción en el espacio público". Madrid: Revista Creatividad y Sociedad, No. XVII, September 2011. Retrieved from: http://www.creatividadysociedad.com

[9] Palacios Garrido, Alfredo. "El arte comunitario: origen y evolución de las prácticas artísticas colaborativas". Arteterapia: Papeles de arteterapia y educación artística para la inclusión social, 4, 197-211. 2009. 